\title{
Affonso do Prado Seabra (1928-2012)
}

\author{
por Angelo da Cunha Pinto
}

Affonso do Prado Seabra formou-se em Farmácia, em 1948, pela Universidade do Brasil (UB) e recebeu o título de Mestre em Ciências, em 1954, pela University of Wisconsin, nos Estados Unidos. Após retornar dos EUA com o mestrado em Bioquímica sob a supervisão de Herold Deutsch, Affonso Seabra foi ser Regente da disciplina Química Orgânica II da Faculdade de Farmácia da UB. Em 1964 concorreu a Cadeira de Química Orgânica e Biológica com a Tese de Livre Docência intitulada "Estudos sôbre a Aromatização dos Compostos Perfluoroalicíclicos", cuja parte experimental foi desenvolvida na Universidade de Birmingham, na Inglaterra, com bolsa do British Council. Ao voltar ao Brasil depois de um período como Professor Visitante na Universidade de Birmingham, Seabra incorporou-se ao recém criado Centro de Pesquisas de Produtos Naturais (CPPN), onde ao lado de Walter B. Mors, Benjamin Gilbert, Joaquim Martins Ferreira Filho, Keith S. Keith Jr e Paulo da Silva Lacaz ajudou a montar a primeira Central Analítica do País, que durante muito tempo foi referência na química brasileira, quando ainda não se falava de equipamentos multiusuários. $\mathrm{A}$ Central Analítica do CPPN está na raia da moderna fitoquímica brasileira e foi de grande importância para o surgimento, no país, de uma nova geração de químicos de produtos naturais com projeção internacional. Seabra foi o grande artífice da transformação do CPPN no atual Núcleo de Pesquisas de Produtos Naturais (NPPN), na época em que Luiz Renato Caldas era o Reitor da Universidade Federal do Rio de Janeiro (UFRJ), e foi seu Diretor entre 1979 e 1983.

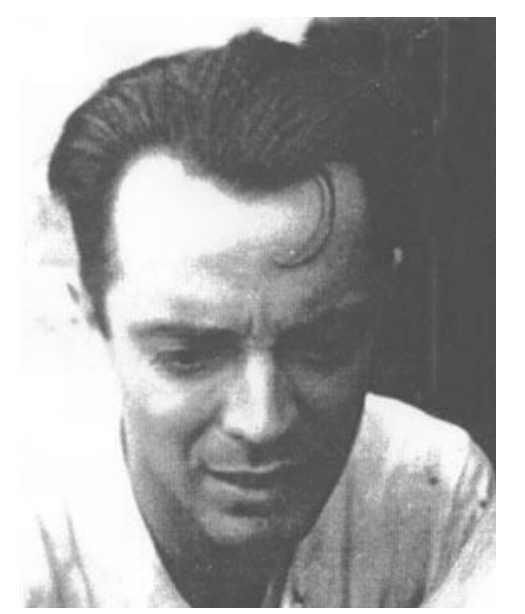

Affonso Seabra foi um dos pioneiros da criação dos cursos de pós-graduação (PG) de Química no Brasil, sendo docente e orientador do curso de PG de Química Orgânica do Instituto de Química da UFRJ, o primeiro da área de Química no Brasil. A sexta dissertação de mestrado desse curso, intitulada "Pirólise de sais básicos de cobre do ácido benzóico, defendida por Carlos Camiza Fortes, em 1967, foi orientada por ele e pelo Professor Warner Bruce Kover. Durante pouco mais de 20 anos Seabra foi membro titular do Conselho de pesquisas e Ensino para Graduados (CEPG), em um período em que estavam sendo criados os primeiros cursos de pós-graduação da UFRJ.

Mas do que toda a sua importância para a Química de produtos Naturais brasileira e da sua participação intensa na criação dos primeiros cursos de pósgraduação da UFRJ, Affonso Seabra tinha o dom de encantar a quem o escutasse, fossem seus ouvintes crianças, adolescentes ou adultos.

Durante muitos anos, até sua aposentadoria na UFRJ, Seabra ocupou o laboratório do final do corredor do NPPN no Centro de Ciências da Saúde (CCS), onde isoladamente se dedicava, como se estivesse em um monastério, ao desenvolvimento de processos de separação e purificação de produtos naturais por cromatografia líquida de alta eficiência (CLAE) de constituintes químicos de extratos vegetais, principalmente de corantes naturais. Não foram raras as vezes que ao sair do laboratório parecia estar saindo de uma batalha sangrenta ou de uma cerimônia índigena tal era o estado de seu jaleco manchado de vermelho de cima a baixo por bixina, o corante extraído do arbusto Bixa orelana, o urucum. $O$ pó das sementes do urucum é matéria corante que os indígenas brasileiros usam até os dias de hoje para se pintarem de vermelho em suas cerimônias.

Mas do que seus trabalhos científicos, seu papel na criação 
dos cursos de pós-graduação na UFRJ, seu pioneirismo na cromatografia líquida de alta eficiência, os livros que escreveu sobre os primeiros programas para edição de texto dos primeiros microcomputadores usados no Brasil, o Professor Affonso do
Prado Seabra foi um verdadeiro MESTRE e um grande contador de estórias.

Universidade Federal do Rio de Janeiro, Instituto de Química, Centro de Tecnologia, Bloco A, CEP 21945-990, Cidade Universitária, Rio de Janeiro, Brasil. 